\title{
ICONIC study-conservative versus conventional oxygenation targets in intensive care patients: study protocol for a randomized clinical trial
}

C. C. A. Grim ${ }^{1,2+}$, L. I. van der Wal ${ }^{1,2^{*}+}$, H. J. F. Helmerhorst ${ }^{1,2}$, D. J. van Westerloo ${ }^{1}$, P. Pelosi ${ }^{3,4}$, M. J. Schultz ${ }^{5,6,7}$, E. de Jonge ${ }^{1}$ and for the ICONIC Investigators and PROVE Network

\begin{abstract}
Background: Oxygen therapy is a widely used intervention in acutely ill patients in the intensive care unit (ICU). It is established that not only hypoxia, but also prolonged hyperoxia is associated with poor patient-centered outcomes. Nevertheless, a fundamental knowledge gap remains regarding optimal oxygenation for critically ill patients. In this randomized clinical trial, we aim to compare ventilation that uses conservative oxygenation targets with ventilation that uses conventional oxygen targets with respect to mortality in ICU patients.

Methods: The "Conservat/ve versus CONventional oxygenation targets in Intensive Care patients" trial (ICONIC) is an investigator-initiated, international, multicenter, randomized clinical two-arm trial in ventilated adult ICU patients. The ICONIC trial will run in multiple ICUs in The Netherlands and Italy to enroll 1512 ventilated patients. ICU patients with an expected mechanical ventilation time of more than $24 \mathrm{~h}$ are randomized to a ventilation strategy that uses conservative $\left(\mathrm{PaO}_{2} 55-80 \mathrm{mmHg}(7.3-10.7 \mathrm{kPa})\right)$ or conventional $\left(\mathrm{PaO}_{2} 110-150 \mathrm{mmHg}(14.7-20 \mathrm{kPa})\right)$ oxygenation targets. The primary endpoint is 28 -day mortality. Secondary endpoints are ventilator-free days at day 28, ICU mortality, in-hospital mortality, 90-day mortality, ICU- and hospital length of stay, ischemic events, quality of life, and patient opinion of research and consent in the emergency setting.
\end{abstract}

Discussion: The ICONIC trial is expected to provide evidence on the effects of conservative versus conventional oxygenation targets in the ICU population. This study may guide targeted oxygen therapy in the future.

Trial registration: Trialregister.nl NTR7376. Registered on 20 July, 2018.

Keywords: Mechanical ventilation, Oxygen inhalation therapy, Intensive care, Oxygen, Clinical trial

* Correspondence: L.I.van_der_wal@lumc.nl

${ }^{+}$C. C. A. Grim and L. I. van der Wal are both first author and contributed equally to this work.

'Department of Intensive Care, Leiden University Medical Center, Albinusdreef 2, 2333, ZA, Leiden, The Netherlands

${ }^{2}$ Department of Anesthesiology, Leiden University Medical Center, Albinusdreef 2, 2333, ZA, Leiden, The Netherlands

Full list of author information is available at the end of the article

\section{Administrative information}

\begin{tabular}{ll}
\hline Title $\{1\}$ & $\begin{array}{l}\text { ICONIC-Conservative versus } \\
\text { conventional oxygenation target in } \\
\text { Intensive Care patients: protocol } \\
\text { for a randomized clinical trial }\end{array}$ \\
\hline Trial registration $\{2 \mathrm{a}$ and $\mathbf{2 b}\}$. & $\begin{array}{l}\text { Trial number: NTR7376 on } \\
\text { trialregister.nl }\end{array}$
\end{tabular}

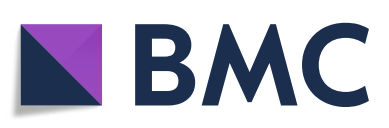

(๑) The Author(s). 2022 Open Access This article is licensed under a Creative Commons Attribution 4.0 International License, which permits use, sharing, adaptation, distribution and reproduction in any medium or format, as long as you give appropriate credit to the original author(s) and the source, provide a link to the Creative Commons licence, and indicate if changes were made. The images or other third party material in this article are included in the article's Creative Commons licence, unless indicated otherwise in a credit line to the material. If material is not included in the article's Creative Commons licence and your intended use is not permitted by statutory regulation or exceeds the permitted use, you will need to obtain permission directly from the copyright holder. To view a copy of this licence, visit http://creativecommons.org/licenses/by/4.0/ The Creative Commons Public Domain Dedication waiver (http://creativecommons.org/publicdomain/zero/1.0/) applies to the data made available in this article, unless otherwise stated in a credit line to the data. 


\section{Administrative information (Continued)}

\begin{tabular}{ll}
\hline Title $\{1\}$ & ICONIC-Conservative versus \\
& conventional oxygenation target in \\
Intensive Care patients: protocol
\end{tabular}
for a randomized clinical trial

Protocol version $\{3\}$

Funding $\{4\}$

Author details $\{5 \mathrm{a}\}$

\begin{abstract}
Name and contact information for the trial sponsor $\{5 b$
\end{abstract}

Role of sponsor $\{5 c\}$

Version 1113 February 2020

This work is part of the research program Replication Studies with project number 401.16.009, which is (partly) financed by the Dutch Research Council (NWO).

C.C.A. Grim* 1,2, L.I. van der Wal* 1,2, H.J. F. Helmerhorst ${ }^{1,2}$, D.J. van Westerloo ${ }^{1}$, P. Pelosi ${ }^{3,4}$, M.J. Schultz ${ }^{5,6,7}$, E. de Jonge ${ }^{1}$, for the ICONIC Investigators and PROVE Network ${ }^{*}$ contributed equally

1. Department of Intensive Care, Leiden University Medical Center Albinusdreef 2, 2333 ZA Leiden, The Netherlands

2. Department of anesthesiology, Leiden University Medical Center, Albinusdreef 2, 2333 ZA Leiden, The Netherlands

3. Department of Surgical Sciences and Integrated Diagnostics, San Martino Policlinico Hospital, IRCCS for Oncology and Neurosciences, Largo R. Benzi 10, 16132, Genoa, Italy 4. Department of Anesthesia and Intensive Care, San Martino Policlinico Hospital, IRCCS for Oncology and Neurosciences, Largo R. Benzi 10, 16132, Genoa, Italy

5. Department of Intensive Care, Amsterdam University Medical Centre, Location AMC, Amsterdam, The Netherlands

6. Mahidol - Oxford Tropical Medicine Research Unit (MORU), Mahidol University, Bangkok, Thailand 7. Nuffield Department of medicine, University of Oxford, Oxford, United Kingdom

\section{E. de Jonge}

Leiden University Medical Center Department of Intensive Care Albinusdreef 2, 2333 ZA Leiden, The Netherlands

Telephone: + 31715265018

E-mail: e.de_jonge@lumc.nl

The sponsor co-designed the ICONIC trial, leads the collection, management, analysis and interpretation of data. The sponsor has a leading role in writing the report and shall be responsible for submitting the ICONIC trial for publication. The funder will have no authority over collection, management, analysis and interpretation of data, writing of the report, and the decision to submit for publication.

\section{Introduction}

Background and rationale $\{6 \mathrm{6}\}$

Arterial oxygenation may be influenced by different factors, including lung function, lung mechanics, ventilator settings, hemodynamics, and the amount of oxygen administered. The risks of hypoxia are wellestablished, and prolonged exposure to severe hyperoxia has also been shown to induce lung injury [1-4]. In two meta-analyses, arterial hyperoxia and liberal use of oxygen therapy were associated with hospital mortality and poor functional outcome in various subsets of critically ill patients $[5,6]$. However, the retrospective nature of the meta-analyzed studies hamper general acceptance of lower target ranges and supraphysiological oxygenation is still frequently pursued in order to avoid hypoxemia. In a Dutch study, the nadir for unadjusted mortality was retrospectively determined at oxygenation levels of 110$150 \mathrm{mmHg}$ [7], but pilot data suggest that more conservative oxygenation targets may also be safe and even improve clinical outcomes [8].

Accordingly, a fundamental knowledge gap regarding optimal oxygenation has been recognized in international literature [9-15].

In a randomized clinical trial on optimal oxygenation in ICU patients that was published in 2016, improved survival was demonstrated in patients who received oxygen according to the conservative strategy $\left(\mathrm{PaO}_{2}\right.$ targeting $70-100 \mathrm{mmHg}$ or arterial oxyhemoglobin saturation $\left(\mathrm{SpO}_{2}\right)$ targeting 94-98\%) in comparison to a conventional control group $\left(\mathrm{PaO}_{2}\right.$ up to $150 \mathrm{mmHg}$ or $\mathrm{SpO}_{2}$ targeting 97-100\%) [16]. This trial was the first randomized clinical study to demonstrate a potential harm of liberal oxygen administration, which earlier had been suggested by observational and preclinical studies [17-21].

However, after this first RCT, three comparable trials have been completed that did not support the previous findings that favored lower oxygenation targets [22-24]. Thus, uncertainty still exists on optimal oxygenation targets in ICU patients.

\section{Objectives $\{7\}$}

As a replication study, we have set up a multicenter trial comparing conservative and conventional oxygenation targets in ICU patients, to confirm findings from a previous study that showed improved survival in ICU patients treated with lower oxygenation targets [16]. To that end, we applied similar in- and exclusion criteria and similar oxygenation targets.

\section{Trial design $\{8\}$}

The ICONIC study is an investigator-initiated, multicenter, international, open-label, parallel, 1:1 randomized 
clinical two-arm equivalence trial in mechanically ventilated ICU patients.

\section{Methods: participants, interventions, and outcomes}

Study setting $\{9\}$

Patients are recruited from ICUs from participating hospitals, academic and non-academic, in Europe. The participating hospitals are as follows:

- Leiden University Medical Centre, Leiden, The Netherlands

- Medisch Centrum Leeuwarden, Leeuwarden, The Netherlands

- Martini Hospital, Groningen, The Netherlands

- Amsterdam University Medical Centre, Amsterdam, The Netherlands

- Ikazia Hospital, Rotterdam, The Netherlands

- Reinier de Graaf Gasthuis, Delft, The Netherlands

- Medisch spectrum Twente, Enschede, The Netherlands

- Diakonessenhuis, Utrecht, The Netherlands

- San Martino Hospital, Genoa, Italy

\section{Eligibility criteria $\{10\}$}

\section{Inclusion criteria}

In order to be eligible to participate in this study, a subject must meet all of the following criteria:

- Age $\geq 18$ years

- Admission to an ICU participating in this study

- Need for intubation and mechanical ventilation

- Expected mechanical ventilation time of $24 \mathrm{~h}$ or longer

- Inclusion within $2 \mathrm{~h}$ after start of invasive ventilation in the ICU or if previously intubated and ventilated within $2 \mathrm{~h}$ after admission to the ICU

\section{Exclusion criteria}

A potential subject who meets any of the following criteria will be excluded from participation in this study:

- Readmission to the ICU within the same hospital admission

- Prior ICONIC study inclusion

- Invasive ventilation longer than $12 \mathrm{~h}$ directly preceding admission

- Decision to withhold life-sustaining treatment at the time of inclusion

- Acute respiratory distress syndrome (ARDS) with a $\mathrm{PaO}_{2} / \mathrm{FiO}_{2}$ ratio less than $150 \mathrm{mmHg}$

- Acute decompensation of chronic obstructive pulmonary disease (COPD) and chronic hypoxemia

- Use of home oxygen therapy
- Severe not rapidly reversible low cardiac output shock (for example: cardiac index $\leq 2 \mathrm{~L} / \mathrm{min} / \mathrm{m}^{2}$ )

- Documented severe pulmonary hypertension

- Veno-arterial extracorporeal membrane oxygenation (VA-ECMO)

- Underlying disease indication for hyperoxygenation (for example: carbon monoxide intoxication, decompression sickness, gas embolism)

- Severe anemia (hemoglobin $<4.0 \mathrm{mmol} / \mathrm{l}$ ) that is not rapidly reversible (e.g., if blood transfusions are not possible or not allowed for religious reasons)

- Uncontrollable intracranial hypertension

- Participation in other interventional trials which could influence ICONIC study intervention and/or endpoints

- Suspected or confirmed pregnancy

\section{Who will take informed consent? $\{26 \mathrm{a}\}$}

Informed consent will be obtained according to local legal regulations. Informed consent will be obtained, if possible, prior to start of intervention. However, due to the emergency setting of this trial, this will occur in the minority of subjects. For the majority of subjects, inclusion will take place in an emergency setting when the patient is incapacitated and deferred consent from a proxy will be obtained as soon as possible. Information about the trial will be given by the treating physician to the proxy. After deferred proxy consent is obtained, decisional capacity of the participant will be assessed frequently and when regained during the ICU stay deferred subject consent must be obtained.

If the patient dies before informed consent or deferred (proxy or subject) consent is obtained, the study data will be used. The Dutch central committee of research in humans (Centrale Commissie Mensgeboden Onderzoek (CCMO)) states that legal representation of a patient ends after death and that therefore the obligation to obtain signed consent no longer applies after death of the patient [25].

\section{Additional consent provisions for collection and use of participant data and biological specimens $\{26 \mathrm{~b}\}$}

This trial does not involve collecting biological specimens for storage.

\section{Interventions}

Explanation for the choice of comparators $\{6 \mathrm{~b}\}$

The comparators were chosen based upon previously found oxygenation targets associated with greater survival in ICU patients $[8,26]$ and to have sufficient contrast in $\mathrm{PaO}_{2}$ between the two randomization groups. 


\section{Intervention description $\{11 \mathrm{a}\}$}

In patients randomized to the "conservative-targets" arm, oxygenation will be targeted at $\mathrm{PaO}_{2} 55-80 \mathrm{mmHg}$ $(7.3-10.7 \mathrm{kPa})$. Because $\mathrm{PaO}_{2}$ is not continuously measured, oxygenation targets can be steered on $\mathrm{SpO}_{2}$ in between $\mathrm{PaO}_{2}$ measurements. Corresponding $\mathrm{SpO}_{2}$ to conservative $\mathrm{PaO}_{2}$ targets needs to be determined per individual patient (usually approximately 91-94\%).

Patients randomized to the "conventional-targets" arm, oxygenation will be targeted at $\mathrm{PaO}_{2}$ between 110 and $150 \mathrm{mmHg} \quad(14.7-20 \mathrm{kPa})$. Corresponding $\mathrm{SpO}_{2}$ to conventional $\mathrm{PaO}_{2}$ targets will also be determined per individual patient (usually approximately 96-100\%).

\section{Invasive ventilation}

The allowed ventilation modes are volume-controlled ventilation, pressure-controlled ventilation, pressure support ventilation, closed loop ventilation, and combined modes. Furthermore, INTELLiVENT-ASV (Hamilton Medical AG, Bonaduz, Switzerland) is allowed with the automatic oxygenation $\left(\mathrm{FiO}_{2}\right.$ and PEEP) adjustment turned off.

The inspired oxygen fraction $\left(\mathrm{FiO}_{2}\right)$ and positive endexpiratory pressure (PEEP) values are determined and titrated by means of the pre-specified and randomly assigned oxygenation targets. The respiratory rate is adjusted to maintain a blood $\mathrm{pH}$ of 7.20 to 7.45. In case of metabolic acidosis or alkalosis, a lower or higher than normal $\mathrm{PaCO}_{2}$ can be accepted, left to the discretion of the attending physician. The lowest level of PEEP is 5 $\mathrm{cmH}_{2} \mathrm{O}$; recommended $\mathrm{FiO}_{2}-\mathrm{PEEP}$ combinations are provided in Table 1. Deviation from the table is allowed in individual patients when indicated and is left to the discretion of the attending physician. Recruitment maneuvers are allowed, when deemed necessary by the attending physician.

In both arms, tidal volume is titrated per predicted bodyweight (PBW), which is calculated according to a previously used formula: $50+0.91 \times$ (centimeters of height -152.4 ) for males and $45.5+0.91 \times$ (centimeters of height -152.4 ) for females. Tidal volumes are targeted at 6-8 $\mathrm{ml} / \mathrm{kg}$ PBW.

\section{Weaning}

Daily assessment of the ability to breathe with pressure support ventilation is required as soon as $\mathrm{FiO}_{2} \leq 0.4$ or when the PEEP level and $\mathrm{FiO}_{2}$ level are lower than the day before.

In addition, the ventilator can be switched to pressure support ventilation at any moment if the attending nurse or physician considers the patient awake enough to breathe with pressure support ventilation. Assessment of the ability to breathe with pressure support is also required in case patient-ventilator asynchrony is noticed
Table 1 Recommended combinations of $\mathrm{FiO}_{2}$ and PEEP. Deviation from the table is allowed in individual patients when indicated and is left to the discretion of the attending physician

\begin{tabular}{ll}
\hline $\mathrm{FiO}_{2}$ & PEEP $\left(\mathrm{cmH}_{\mathbf{2}} \mathbf{O}\right)$ \\
\hline 0.21 & 5 \\
0.30 & 5 \\
0.40 & 5 \\
0.40 & 8 \\
0.50 & 8 \\
0.50 & 10 \\
0.60 & 10 \\
0.70 & 10 \\
0.70 & 12 \\
0.70 & 14 \\
0.80 & 14 \\
0.90 & 16 \\
0.90 & 18 \\
1.00 & 18 \\
1.00 & 20 \\
1.00 & 22 \\
1.00 & 24 \\
\hline
\end{tabular}

(ineffective breathing; double triggering, use of accessory respiratory muscles). A patient is assumed to be ready for extubation when the following criteria are met for at least $30 \mathrm{~min}$, and the final decision for extubation is made by the attending physician:

- Responsive and cooperative

- Adequate cough reflex

- $\mathrm{PaO}_{2} / \mathrm{FiO}_{2}$ of $>200 \mathrm{mmHg}$ with $\mathrm{FiO}_{2} \leq 40 \%$

- Respiratory rate of 8 to 30 per minute

- No signs of respiratory distress (i.e., marked accessory muscle use, abdominal paradox, diaphoresis, marked dyspnea)

- Pressure support level $<8 \mathrm{cmH}_{2} \mathrm{O}$

- Hemodynamically stable (systolic blood pressure 80 to $160 \mathrm{mmHg}$ and heart rate 40 to $130 / \mathrm{min}$ ) and no uncontrolled arrhythmia

- Temperature $>36.0$ and $<38.5^{\circ} \mathrm{C}$

If a patient is able to breathe without assistance but subsequently requires additional ventilation within 28 days after randomization, the same oxygenation target protocol is resumed.

\section{After invasive ventilation}

When a patient is extubated, the $\mathrm{PaO}_{2}$ targets should still be pursued within the type of oxygen support for which the patient has a medical indication. High-flow nasal oxygen or non-invasive ventilation should not be 
started solely for the ICONIC study $\mathrm{PaO}_{2}$ targets, because this could influence duration of ICU admission. If this means the $\mathrm{PaO}_{2}$ targets are not achieved after extubation, this should be accepted. The following rules apply:

- For patients randomized to the conventional oxygenation target: always give a nasal cannula with $5 \mathrm{~L}$ of oxygen, except if $\mathrm{PaO}_{2}>150 \mathrm{mmHg}(>20$ $\mathrm{kPa}$ ).

- For patients randomized to the conservative target: preferably no oxygen therapy, except if $\mathrm{PaO}_{2}<55$ $\mathrm{mmHg}(<7.3 \mathrm{kPa})$.

\section{Criteria for discontinuing or modifying allocated interventions $\{11 \mathrm{~b}\}$}

Subjects can leave the study at any time for any reason if they wish to do so without any consequences. The investigator can decide to withdraw a subject from the study for urgent medical reasons. When deferred consent is not obtained after randomization and provisional inclusion of a patient or when a patient withdraws consent. The replacement of the randomization subject will be done in the automated randomization scheme.

To avoid prolonged exposure to very high inspiratory oxygen concentrations, the allocated intervention can temporarily be modified in the conventional $\mathrm{PaO}_{2}$ target group when $\mathrm{FiO}_{2}$ is above $80 \%$ for more than $2 \mathrm{~h}$ and/or PEEP is above $15 \mathrm{cmH}_{2} \mathrm{O}$ for more than $2 \mathrm{~h}$. In order to provide guidance when clinicians are in a situation with high inspiratory oxygen concentrations, we created a flowchart (Fig. 1).

\section{Strategies to improve adherence to interventions $\{11 \mathrm{c}\}$}

At least one blood gas analysis per shift (three per $24 \mathrm{~h}$ ) will be required while mechanically ventilated.

If a participating ICU has difficulty adhering to the oxygenation targets and there is risk of overlap between the groups, the "aiming point $\mathrm{PaO}_{2}$ " provides guidance to the bedside clinicians:

- Conservative arm aiming point $\mathrm{PaO}_{2} 60 \mathrm{mmHg}(8$ $\mathrm{kPa})$

- Conventional arm aiming point $\mathrm{PaO}_{2} 135 \mathrm{mmHg}$ $(18 \mathrm{kPa})$

\section{Relevant concomitant care permitted or prohibited during the trial $\{11 \mathrm{~d}\}$}

Among other concomitant care, sedation, selective oropharyngeal or digestive tract decontamination, thrombosis prophylaxis, fluid regimens, and nutrition follow the local guidelines in each participating ICU and are permitted during the trial.

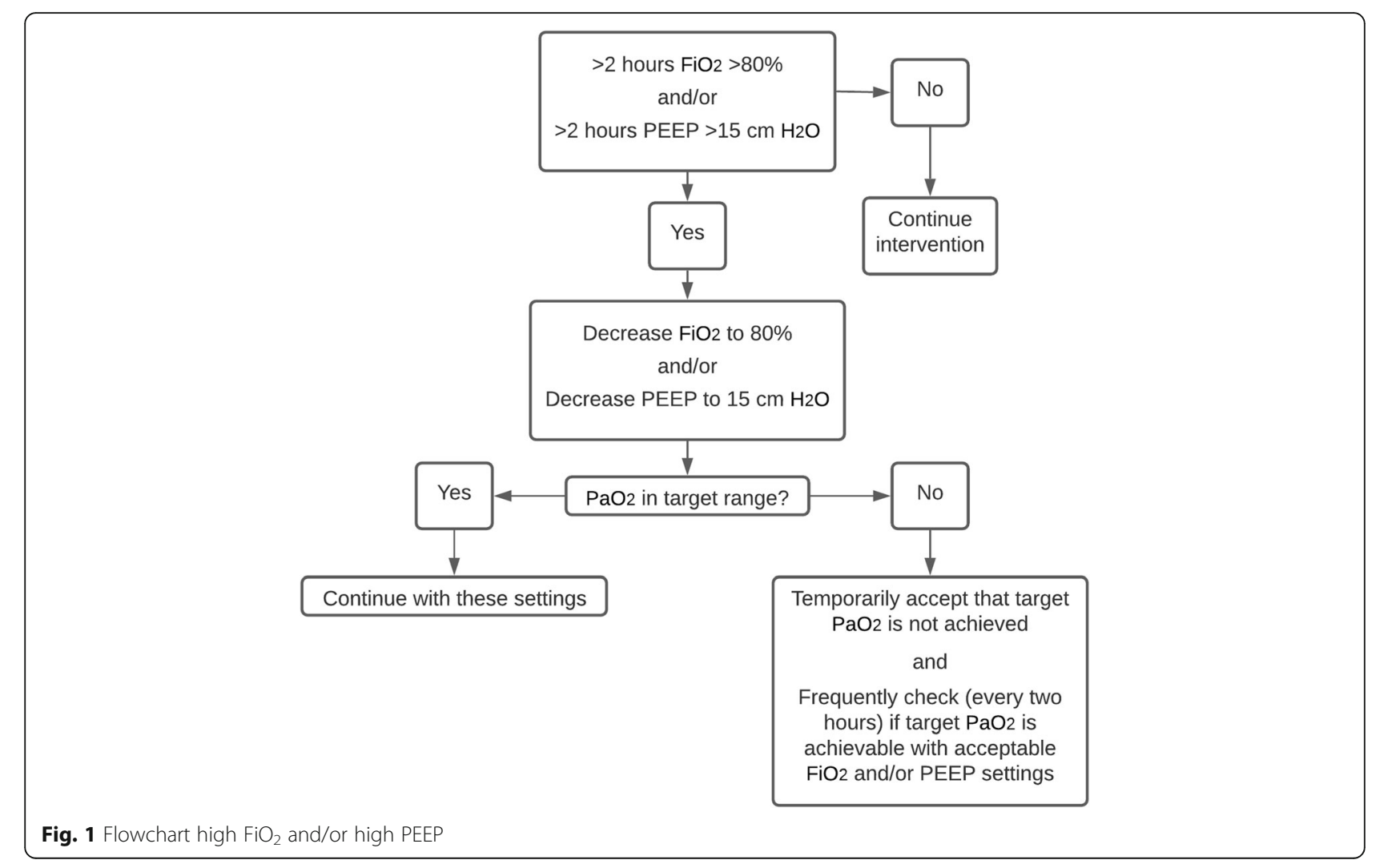


Provisions for post-trial care $\{30\}$

No provisions or restrictions are applicable for post-trial care. The sponsor has an insurance which is in accordance with the legal requirements in the Netherlands (Article $7 \mathrm{WMO}$ ). This insurance provides cover for damage to research subjects through injury or death caused by the study. The insurance applies to the damage that becomes apparent during the study or within 4 years after the end of the study.

\section{Outcomes $\{12\}$}

The primary endpoint is all-cause mortality at 28 days after randomization. The secondary study endpoints are as follows:

- The number of ventilator-free days and alive at day 28 , defined as the number of calendar days from day 1 to day 28 , the patient is alive and breathes without assistance of the mechanical ventilator. Ventilatorfree days are according to the definitions by the Dutch National Intensive Care Evaluation (NICE) registry [27].

- ICU length of stay (LOS)

- Hospital LOS

- ICU mortality

- Hospital mortality

- 90-day mortality

- Ischemic events (cardiac, neurological and peripheral)

Follow-up (in participating subjects from the Netherlands):

- Quality of life at 6 and 12 months

- Patient opinion of research and consent in the emergency setting at 6 months after randomization

Participant timeline $\{13\}$

Participant timeline is shown in Fig. 2.

\section{Sample size $\{14\}$}

Based on an expected mortality in the control group of 24\% (source: Dutch NICE foundation; NICE online [27]), we will include 1512 patients to detect an absolute difference in mortality of $6 \%$ (2-sided, alpha 0.05 , power $80 \%$, similar allocation of subjects to each group and corrected for $4 \%$ dropouts). The choice of $6 \%$ was motivated by the difference of $8 \%$ found in a previous trial [16] comparing conventional to conservative oxygenation targets and what could be considered clinically acceptable.
Recruitment $\{15\}$

All patients admitted to participating ICUs or intubated on participating ICUs will be screened for eligibility.

\section{Assignment of interventions: allocation}

Sequence generation $\{16 \mathrm{a}\}$

Randomization sequence is generated by a dedicated computer randomization software program (Castor EDC, Amsterdam, The Netherlands) using variable block sizes and is stratified per participating center.

Details of blocking are provided in a separate document that is unavailable to those who enroll participants or assign interventions.

\section{Concealment mechanism \{16b\}}

Randomization will be performed using a dedicated, password-protected, SSL-encrypted website (Castor EDC, Amsterdam, The Netherlands).

\section{Implementation $\{16 c\}$}

The allocation sequence is generated by a dedicated computer randomization software program (Castor EDC, Amsterdam, The Netherlands). Patients will be enrolled by local investigators and/or treating physicians in participating ICUs, and the intervention will be randomly assigned by the computer randomization software.

\section{Assignment of interventions: blinding Who will be blinded $\{17 \mathrm{a}\}$}

Due to the nature of the intervention, the clinicians and the outcome assessors are not blinded, but the data analysts will remain blinded.

\section{Procedure for unblinding if needed $\{17 b\}$}

Not applicable, there is no blinding of care providers.

\section{Data collection and management}

Plans for assessment and collection of outcomes \{18a\}

Only data needed to assess primary and secondary objectives will be collected in electronic case report forms and extraction from the patient registry systems. Data will be regularly checked on quality, errors, and outliers and corrected if possible.

Two questionnaires are used for the follow-up of subjects from the Netherlands:

- EQ-5D $[28,29]$

- A self-developed questionnaire assessing patient opinion and experience of the consent procedure of research in the emergency setting, which is a modified and translated version of the questionnaire used in a previous trial [30]. 


\begin{tabular}{|c|c|c|c|c|c|c|c|c|c|}
\hline \multirow[b]{3}{*}{ TIMEPOINT } & \multicolumn{9}{|c|}{ Study period } \\
\hline & \multirow[b]{2}{*}{$\begin{array}{c}\text { Screening } \\
\text { Start of } \\
\text { ventilation } \\
\text { or ICU } \\
\text { admission }\end{array}$} & \multirow[b]{2}{*}{$\begin{array}{c}\text { Randomization } \\
<2 \text { hours after } \\
\text { start of } \\
\text { ventilation or } \\
\text { ICU admission } \\
-24: 00 \\
\end{array}$} & \multicolumn{3}{|c|}{ Post-randomization } & \multicolumn{4}{|c|}{ Follow-up } \\
\hline & & & $\begin{array}{c}\text { Day } \\
0\end{array}$ & $\begin{array}{l}\text { Daily: } \\
\text { Day } \\
1-28\end{array}$ & Discharge & $\begin{array}{c}\text { Day } \\
28\end{array}$ & $\begin{array}{c}\text { Day } \\
90\end{array}$ & \begin{tabular}{|c|}
6 \\
Months
\end{tabular} & $\begin{array}{c}12 \\
\text { Months }\end{array}$ \\
\hline \multicolumn{10}{|l|}{ ENROLLMENT } \\
\hline Eligibility screen & $\mathrm{X}$ & & & & & & & & \\
\hline Deferred consent & & $\mathrm{X}^{*}$ & & & & & & & \\
\hline Allocation & & $\mathrm{X}$ & & & & & & & \\
\hline \multicolumn{10}{|l|}{ INTERVENTIONS } \\
\hline $\begin{array}{l}\text { Conservative } \\
\text { oxygenation }\end{array}$ & & & & $\rightarrow$ & & & & & \\
\hline $\begin{array}{l}\text { Conventional } \\
\text { oxygenation }\end{array}$ & & & & $\rightarrow$ & & & & & \\
\hline \multicolumn{10}{|l|}{ ASSESSMENTS } \\
\hline $\begin{array}{l}\text { Baseline: } \\
\text { demographic } \\
\text { data, date, } \\
\text { location and } \\
\text { reason for } \\
\text { intubation, } \\
\text { medical history, } \\
\text { APACHE score, } \\
\text { SOFA parameters }\end{array}$ & & & $\mathrm{X}$ & & & & & & \\
\hline $\begin{array}{l}\text { Arterial- and } \\
\text { venous blood gas } \\
\text { data }\end{array}$ & & & $\mathrm{X}$ & $\mathrm{X}$ & & & & & \\
\hline Ventilation data & & & $\mathrm{X}$ & $\mathrm{X}$ & & & & & \\
\hline SOFA parameters & & & $X$ & $x$ & & & & & \\
\hline Delirium & & & $X$ & $x$ & & & & & \\
\hline $\begin{array}{l}\text { Type of endpoint: } \\
\text { death, discharge } \\
\text { from ICU, } \\
\text { transferal non } \\
\text { ICONIC, day } 28\end{array}$ & & & & & $\mathrm{X}$ & & & & \\
\hline $\begin{array}{l}\text { Infection: surgical } \\
\text { site, bloodstream, } \\
\text { respiratory tract }\end{array}$ & & & & & $\mathrm{X}$ & & & & \\
\hline Ischemic events & & & & & $\mathrm{X}$ & & & & \\
\hline Transfusion & & & & & $\mathrm{X}$ & & & & \\
\hline $\begin{array}{l}\text { Live status: dead } \\
\text { or alive }\end{array}$ & & & & & & $\mathrm{X}$ & $\mathrm{X}$ & & \\
\hline $\begin{array}{l}\text { Experience of } \\
\text { consent } \\
\text { procedure }\end{array}$ & & & & & & & & $\mathrm{X}$ & $\bar{X}$ \\
\hline Quality of life & & & & & & & & $\mathrm{X}$ & $X$ \\
\hline
\end{tabular}

Fig. 2 Schedule of enrollment, intervention, and assessments

Subjects will receive these questionnaires per mail or e-mail.

\section{Plans to promote participant retention and complete follow-up $\{18 b\}$}

No or minimal losses to follow-up for the primary outcome is anticipated. Complete-case analysis will be carried out for all the outcomes. However, if more than $5 \%$ of missing data is found for the primary outcome, a sensitivity analysis using multiple imputations will be carried out.

\section{Data management $\{19\}$}

All patients will be allocated with a random patient identification code. Patient-identifying data will be omitted. The codebook will be stored digitally and in paper and will be safeguarded by the site investigator. The paper version will be stored behind a lock and the digital form will be encrypted. Source data will be stored at the specific study site where it originated and will be safeguarded by the site investigator. Data sent to the project leader or principal investigator will only contain this code and will not contain patient-identifying information.

\section{Confidentiality $\{27\}$}

A codebook of enrolled participants will be collected and stored digitally or in paper, encrypted or behind a lock. The personal information in these files will not be shared with other investigators.

Plans for collection, laboratory evaluation, and storage of biological specimens for genetic or molecular analysis in this trial/future use $\{33\}$

Not applicable, no biological specimens are collected. 


\section{Statistical methods}

Statistical methods for primary and secondary outcomes $\{20 \mathrm{a}\}$

\section{Primary outcome}

The primary endpoint, all-cause mortality at day 28, is analyzed using Kaplan Meier. The statistical analysis will be based on the intention-to-treat principle, with patients analyzed according to their assigned treatment arms, except for cases withdrawn or without informed consent. The primary outcome will be assessed using a two-sided superiority hypothesis test, with a significance level of 0.05 and presented with two-sided 95\% confidence intervals. In addition, we will perform a perprotocol analysis to check for robustness of results. The per-protocol group analysis only considers patients of the conservative group if $50 \%$ or more of the $\mathrm{PaO}_{2} \mathrm{~S}$ in the blood gas analysis is equal to or below $10.7 \mathrm{kPa}(80$ $\mathrm{mmHg}$ ), and patients of the conventional group if $50 \%$ or more of the $\mathrm{PaO}_{2}$ in the blood gas analysis is equal to or above $14.7 \mathrm{kPa}(110 \mathrm{mmHg})$.

\section{Secondary outcome}

Secondary endpoints that fall under the category of continuous normally distributed variables will be expressed as frequencies and percentages. Differences between groups in continuous normally distributed variables will be expressed by their means and standard deviations or when not normally distributed, as medians and their interquartile ranges. Secondary endpoints that fall under the category of categorical variables will be expressed as frequencies and percentages. Differences between groups in continuous variables will be analyzed with Student's $t$ test or, if continuous data is not normally distributed, the Mann-Whitney $U$ test will be used. Categorical variables will be compared with the chi-squared test or Fisher's exact test, as appropriate. Statistical significance is considered to be at a $p$-value < 0.05 with a two-sided test. When appropriate, statistical uncertainty will be expressed by $95 \%$ confidence levels. In addition to the unadjusted $p$-values for secondary outcomes, a procedure will be applied to control for multiple testing.

All statistical analyses will be performed with the $R$ language and environment for statistical computing ( $R$ Foundation for Statistical Computing, Vienna, Austria).

\section{Interim analyses $\{21 \mathrm{~b}\}$}

No planned interim analysis will be performed. The data safety monitoring board (DSMB) will analyze a proxy endpoint, in-hospital mortality, for subject safety.

The stopping guidelines are defined as follows: The primary endpoint will be analyzed for safety reasons if a difference in in-hospital mortality of $>6 \%$ is found with a $p$-value $<0.005$ (chi-square test). The study will only be stopped early for safety reasons if a difference in primary endpoint (28-day mortality) is found of $>6 \%$ with a $p$-value of $<0.001$.

\section{Methods for additional analyses (e.g., subgroup analyses) \{20b\}}

Subgroup analyses are planned to investigate the effects of oxygenation targets on the primary endpoint in the following subgroups: ARDS at ICU admission, patients with sepsis as reason for admission, patients with stroke, patients with myocardial infarction, and patients with elevated plasma lactate $(>2 \mathrm{mmol} / \mathrm{l})$.

\section{Methods in analysis to handle protocol non-adherence} and any statistical methods to handle missing data $\{20 \mathrm{c}\}$ Analysis will primarily be performed following the intention-to-treat principle. To handle protocol nonadherence, a secondary per-protocol analysis will be performed.

No or minimal losses to follow-up for the primary outcome is anticipated. Complete-case analysis will be carried out for all the outcomes. However, if more than 5\% of missing data is found for the primary outcome, a sensitivity analysis using multiple imputations will be carried out.

Plans to give access to the full protocol, participant-level data, and statistical code $\{31 \mathrm{c}\}$

The full protocol will be publicly accessible. Upon reasonable request, the dataset and statistical code will be made available.

\section{Oversight and monitoring}

Composition of the coordinating center and trial steering committee $\{5 \mathrm{~d}\}$

The coordinating center and steering committee will provide trial oversight and is composed of the principal investigator, leading investigators, and experts of ventilation who contributed to the design and revision of the study protocol. The leading investigators are responsible for the daily management of the trial and provide assistance to participating ICUs in training in study-related procedures for the local staff, trial management, data management, and monitoring. Local investigators in each site will screen the patients who require mechanical ventilation and check if they are eligible for participation, perform randomization, supervise data collection, and ensure adherence to the ICH-GCP guidelines during the trial.

Composition of the data monitoring committee, its role and reporting structure $\{21 \mathrm{a}\}$

An independent Data Safety and Monitoring Board (DSMB) watches over the ethics of conducting the study 
in accordance with the Declaration of Helsinki and monitors safety parameters and the overall conduct of the study. The DSMB is composed of three independent individuals. The DSMB will meet at least yearly. No competing interests were reported by the DSMB.

\section{Adverse event reporting and harms $\{22\}$}

Adverse events (AE) are defined as any undesirable experience occurring to a subject during the study, whether or not considered related to the trial procedure and intervention strategies. Since this is a low-risk study in critically ill patients, comparing two currently used $\mathrm{PaO}_{2}$ targets, additional undesirable events related to the study protocol are not anticipated. Therefore, we will only register serious adverse events (SAEs) and will not record AEs.

Because this is a study in critically ill patients, SAEs are expected to occur frequently. Therefore, the following SAEs are not considered untoward in this population and will not be treated as SAE:

- Death not related to the study intervention

- Infections

- Bleeding

- Organ failure

The following events occurring during ICU admission will be treated and registered as SAE:

- $\mathrm{PaO}_{2} \leq 5 \mathrm{kPa}(37.5 \mathrm{mmHg})$

- Ischemic events (limbs, cerebral, myocardial, intestinal)

- In-hospital cardiac arrest (IHCA)

- $\mathrm{SpO}_{2}<80 \%$ for longer than 10 min (not explained by technical failure)

- Death possibly related to the study intervention

The site investigator will report all SAEs to the leading investigator without undue delay after obtaining knowledge of the events.

The sponsor or lead investigator will report the SAEs through the web portal to the accredited ethical reviewing board that approved the protocol, within 7 days of first knowledge for SAEs that result in death or are life threatening followed by a period of maximum of 8 days to complete the initial preliminary report. All other SAEs will be reported within a period of maximum 15 days after the sponsor has first knowledge of the serious adverse events.

\section{Frequency and plans for auditing trial conduct $\{23\}$}

On-site monitoring will comprise controlling presence and completeness of the research files and the informed consent forms, source data checks will be performed as described in the monitoring plan. Every participating center will be visited at least once every year.

Monitoring in the Leiden University Medical Center, the coordinating site, will be executed by internal monitors of the LUMC according to the monitor plan. Independent monitoring of participating sites will be arranged by the coordinating investigator and principal investigator.

\section{Plans for communicating important protocol amendments to relevant parties (e.g., trial participants, ethical committees) $\{25\}$}

A substantial amendment is defined as an amendment to the terms of the ethical reviewing board application, or to the protocol or any other supporting documentation, that is likely to affect to a significant degree:

- The safety or physical or mental integrity of the subjects of the trial;

- The scientific value of the trial;

- The conduct or management of the trial; or

- The quality or safety of any intervention used in the trial.

All substantial amendments will be notified to the ethical reviewing board and to the competent authority.

\section{Dissemination plans $\{31 \mathrm{a}\}$}

The study protocol and analysis plan will be published before start of the study on trialregister.nl (trial number: 7376). The results of the study will be presented to (inter-) national scientific journals, professional societies, and guideline committees. We will submit analyses to scientific journals in the field of Intensive Care medicine as well as anesthesiology, since both ICU physicians and anesthesiologists apply ventilation in the ICU setting. The results of this study will be disclosed unreservedly according to the Central Committee on Research Involving Human Subjects (CCMO) statement on publication policy (http://www.ccmo.nl/attachments/ files/ccmo-statement-publicatiebeleid-3-02-en.pdf).

Material for public dissemination will be submitted to the sponsor for review prior to submission for publication. Each study site will provide one co-author, when at least ten subjects have been included. If more than one hundred subjects have been included or reasonable efforts have been made to reach this number the study site will provide two co-authors. The co-authors will be determined in accordance with general accepted academic standards for authorship. Prior to submission, co-authors will look through the manuscript. No parties involved have veto right. 


\section{Discussion}

The ICONIC study is a randomized clinical trial that is sufficiently powered to investigate whether a difference in outcome exists between mechanically ventilated ICU patients targeted at conservative or conventional oxygenation. Our aim is to replicate the study that was conducted by Girardis et al., in order to see if we would come to equivocal conclusions. After starting the ICONIC trial, the evidence of the previously mentioned Italian trial [16] and before mentioned studies resulted in clinical practice guidelines that emphasized a more conservative approach of oxygen therapy [6, 22-24, 26]. This encouraged the start of several other randomized trials, including the ICU-ROX, $\mathrm{LOCO}_{2}$, the HOT-ICU, and the present trial.

The ICU-ROX investigators compared conservative oxygen therapy (targeting $\mathrm{SpO}_{2}$ of $90-96 \%$ ) to usual care $\left(\mathrm{SpO}_{2}>90 \%\right)$ in 1000 adults undergoing mechanical ventilation in Australia and New Zealand. Conservative oxygen therapy did not improve ventilator-free days or survival in mechanically ventilated adults. However, the interventions compared were conservative oxygen therapy and usual care targeting $\mathrm{SpO}_{2}$, and the actual difference in achieved $\mathrm{SpO}_{2}$ values between the two groups was minimal. Possibly the chosen target ranges were too close and did not allow sufficient discrimination, reducing the chance to detect any difference in endpoint.

The $\mathrm{LOCO}_{2}$ trial planned to randomize 850 French ARDS patients to conservative (target $\mathrm{PaO}_{2}$ 55-70 mmHg; target $\mathrm{SpO}_{2}$ 88-92\%) or liberal oxygen therapy (target $\mathrm{PaO}_{2}$ 90-105 mmHg; target $\mathrm{SpO}_{2} \geq 96 \%$ ). However, the trial was stopped prematurely after enrolling 205 patients because of safety concerns due to ischemic events occurring in the conservative group.

Lastly, the most recent published trial from the HOTICU group randomized 2928 mechanically ventilated ICU patients to a $\mathrm{PaO}_{2}$ of either $60 \mathrm{mmHg}$ or a $\mathrm{PaO}_{2}$ of $90 \mathrm{mmHg}$. No difference in death within 90 days was found. A limitation of this study was that possibly two "normoxia" targets were compared and that there was limited contrast in the applied intervention.

The most recent trials do not support the previously found benefits of conservative oxygen use [16]. Potential explanation for the negative findings in later trials is the lack of contrast between the oxygenation targets (intervention) in both study groups. To add, no truly hyperoxic targets were included in the negative trials. In the literature, hyperoxia or higher targets are either defined as an $\mathrm{PaO}_{2}$ of $>100 \mathrm{mmHg}$, an $\mathrm{PaO}_{2}>150$ mmHg or even an $\mathrm{PaO}_{2}$ of $>300 \mathrm{mmHg}$ [31-35]. In the study by Girardis that did show benefit in the lower oxygenation group, the $\mathrm{PaO}_{2}$ target in the control group was up to $150 \mathrm{mmHg}$, thus more hyperoxic than the oxygenation targets in the negative RCTs.
In order to build on previously published, results we hope to answer questions that remained unanswered in existing literature. Therefore, one of the strengths of the ICONIC is that we chose targets that are further apart, namely $55-80 \mathrm{mmHg}$ vs $110-150 \mathrm{mmHg}$. To add, to maximize generalizability, we plan to not only focus on ARDS but include patients with a variety of conditions. Due to evidence of ischemia in the conservative group in the $\mathrm{LOCO}_{2}$ trial, we will monitor occurrence of ischemic events (cardiac, intestinal, cerebral, and peripheral) closely.

A limitation of this study can be the difficulty for patients to reach their target range. The ability to reach a higher target range highly depends on the lung function and underlying disease. Therefore, it might be possible that a patient is randomized to the higher group but due to underlying condition or clinical deterioration is not able to reach the higher target. We attempted to minimize this risk by excluding patients with ARDS and a $\mathrm{P} / \mathrm{F}$ ratio $<20$, but we can unfortunately not anticipate on the risk of future clinical deterioration. Also patients with healthy lungs that are randomized in the lower oxygenation group might easily reach an $\mathrm{SpO}_{2}$ of above $80 \mathrm{mmHg}$ with the slightest additional oxygen. For this reason, patients with an expected duration of ventilation of less than $24 \mathrm{~h}$ are also excluded. Another limitation of this study could be that we focus on the whole ICU population instead of subgroups. Suggestions in literature have been made that some subgroups might benefit from a higher or lower oxygenation strategy, but a recent mini-review by Demiselle et al. shows that when pooling the data from different subgroups that still no "optimal" oxygenation target for subgroups can be chosen [36]. Also groups in which a specific oxygen target is proven to be beneficial, for example in COPD patients, were excluded from the study.

In conclusion, the ICONIC study is an investigatorinitiated international randomized clinical trial aiming to answer the question how to target oxygen therapy by investigating whether a difference in outcome exists between mechanically ventilated ICU patients targeted at conservative or conventional oxygenation.

\section{Trial status}

Protocol version number: Version 11, 13 February 2020

Date recruitment began: 19 November 2018

Approximate date when recruitment will be completed: 1 January 2022

\section{Abbreviations}

AE: Adverse event; ARDS: Acute respiratory distress syndrome; APACHE: Acute Physiology And Chronic Health Evaluation; CCMO: Central Committee on Research Involving Human Subjects; in Dutch: Centrale Commissie Mensgebonden Onderzoek; COPD: Chronic obstructive pulmonary disease; DSMB: Data Safety Monitoring Board; (e)CRF: (Electronic) Case Report Form; $\mathrm{FiO}_{2}$ : Fraction of inspired oxygen; $\mathrm{Hb}$ : Hemoglobin; 
ICU: Intensive care unit; IHCA: In-hospital cardiac arrest; LOS: Length of stay; LUMC: Leiden University Medical Centre; NICE: National Intensive Care Evaluation; NWO: Dutch research council; $\mathrm{PaO}_{2}$ : Partial pressure of arterial oxygen; PBW: Predicted body weight; PEEP: Positive end-expiratory pressure; PROVE: PROtective VEntilation; RCT: Randomized clinical trial; SAE: Serious adverse event; SOFA: Sequential Organ Failure Assessment;

$\mathrm{SpO}_{2}$ : Oxyhemoglobin saturation; VA-ECMO: Veno-arterial extracorporeal membrane oxygenation; WMO: Medical Research Involving Human Subjects Act (in Dutch: Wet Medisch-wetenschappelijk Onderzoek met Mensen)

\section{Acknowledgements}

\section{ICONIC investigators:}

M.R. del Prado, Leiden University Medical Center, Department of Intensive Care, Leiden, The Netherlands. J. Wigbers, Leiden University Medical Center, Department of Intensive Care, Leiden, The Netherlands. M.J. Sigtermans, Diakonessenhuis, Department of Intensive Care, Utrecht, The Netherlands. L. Dawson, Reinier de Graaf Gasthuis, Department of Intensive Care, Delft, The Netherlands. P.L.J. van der Heijden, Reinier de Graaf Gasthuis, Department of Intensive Care, Delft, The Netherlands. E.Y. Schriel-van den Berg, Reinier de Graaf Gasthuis, Department of Intensive Care, Delft, The Netherlands. B.G. Loef, Martini Ziekenhuis, Department of Intensive Care, Groningen, The Netherlands. A. C. Reidinga, Martini Ziekenhuis, Department of Intensive Care, Groningen, The Netherlands. E. de Vreede, Martini Ziekenhuis, Department of Intensive Care, Groningen, The Netherlands. J. Qualm, Martini Ziekenhuis, Department of Intensive Care, Groningen, The Netherlands. E.C. Boerma, Medisch Centrum Leeuwarden, Department of Intensive Care, Leeuwarden, The Netherlands. H. Rijnhart - de Jong, Medisch Centrum Leeuwarden, Department of Intensive Care, Leeuwarden, The Netherlands. M. Koopmans, Medisch Centrum Leeuwarden, Department of Intensive Care, Leeuwarden, The Netherlands. A.D. Cornet, Medisch Spectrum Twente, Department of Intensive Care, Enschede, The Netherlands. T. Krol, Medisch Spectrum Twente, Department of Intensive Care, Enschede, The Netherlands. M. Rinket, Medisch Spectrum Twente, Department of Intensive Care, Enschede, The Netherlands. J.W. Vermeijden, Medisch Spectrum Twente, Department of Intensive Care, Enschede, The Netherlands. A. Beishuizen, Medisch Spectrum Twente, Department of Intensive Care, Enschede, The Netherlands. F. J. Schoonderbeek, Ikazia Ziekenhuis, Department of Intensive Care, Rotterdam, The Netherlands. J. van Holten, Ikazia Ziekenhuis, Department of Intensive Care, Rotterdam, The Netherlands. A.M. Tsonas, Amsterdam University Medical Centre, Department of Intensive Care, Amsterdam, The Netherlands. M. Botta, Amsterdam University Medical Centre, Department of Intensive Care, Amsterdam, The Netherlands. T. Winters, Amsterdam University Medical Centre, Department of Intensive Care, Amsterdam, The Netherlands. J. Horn, Amsterdam University Medical Centre, Department of Intensive Care, Amsterdam, The Netherlands. F. Paulus, Amsterdam University Medical Centre, Department of Intensive Care, Amsterdam, The Netherlands. M. Loconte, San Martino Hospital, Department of Intensive Care, Genoa, Italy. D. Battaglini, San Martino Hospital, Department of Intensive Care, Genoa, Italy. L. Ball, San Martino Hospital, Department of Intensive Care, Genoa, Italy. I. Brunetti, San Martino Hospital, Department of Intensive Care, Genoa, Italy

The ICONIC trial is part of the PROVE Network.

\section{Authors' contributions}

EJ is the Principal Investigator, conceived the study, and led the proposal, funding, and protocol development. HH, DW, MS, and PP contributed to study design, protocol development, and development of the proposal. CG and LIW are the coordinating investigators, contributed to study design, and wrote the protocol and manuscript. All authors contributed to revision of the manuscript and approved the submitted version.

\section{Funding}

This Trial was funded by the Leiden University Medical Centre. The trial was co-funded by The Dutch research council (Nederlandse organisatie voor wetenschappelijk onderzoek (NWO)). Neither trial participants nor research personnel received any fees for contributing to this trial.

\section{Availability of data and materials}

Upon reasonable request, the dataset and statistical code will be made available by the principal investigator.

\section{Declarations}

\section{Ethics approval and consent to participate}

The trial protocol is written and will be conducted in accordance to the Declaration of Helsinki (2013). The ethical approval has been granted by local medical ethics committee of Leiden, Den Haag, and Delft in the Netherlands (committee reference number P18.109). In Italy, local approval will be obtained. Informed consent will be obtained from all participants, using a deferred consent principle as described in paragraph 26a.

\section{Consent for publication}

Not applicable, since no personally identifiable information is used.

\section{Competing interests}

The authors declare that they have no competing interests.

\section{Author details}

${ }^{1}$ Department of Intensive Care, Leiden University Medical Center, Albinusdreef 2, 2333, ZA, Leiden, The Netherlands. ${ }^{2}$ Department of Anesthesiology, Leiden University Medical Center, Albinusdreef 2, 2333, ZA, Leiden, The Netherlands. ${ }^{3}$ Department of Surgical Sciences and Integrated Diagnostics, San Martino Policlinico Hospital, IRCCS for Oncology and Neurosciences, Largo R. Benzi 10, 16132 Genoa, Italy. ${ }^{4}$ Department of Anesthesia and Intensive Care, San Martino Policlinico Hospital, IRCCS for Oncology and Neurosciences, Largo R. Benzi 10, 16132 Genoa, Italy. ${ }^{5}$ Department of Intensive Care, Amsterdam University Medical Centre, Location AMC, Amsterdam, The Netherlands. ${ }^{6}$ Mahidol - Oxford Tropical Medicine Research Unit (MORU), Mahidol University, Bangkok, Thailand.

${ }^{7}$ Nuffield Department of medicine, University of Oxford, Oxford, UK.

Received: 30 July 2021 Accepted: 29 January 2022

Published online: 13 February 2022

\section{References}

1. Altemeier WA, Sinclair SE. Hyperoxia in the intensive care unit: why more is not always better. Curr Opin Crit Care. 2007;13(1):73-8.

2. Sinclair SE, Altemeier WA, Matute-Bello G, Chi EY. Augmented lung injury due to interaction between hyperoxia and mechanical ventilation. Crit Care Med. 2004;32(12):2496-501.

3. Helmerhorst HJ, Schultz MJ, van der Voort PH, de Jonge E, van Westerloo DJ. Bench-to-bedside review: the effects of hyperoxia during critical illness. Crit Care. 2015;19:284.

4. Helmerhorst HJ, Schultz MJ, van der Voort PH, Bosman RJ, Juffermans NP, de Jonge $E$, et al. Self-reported attitudes versus actual practice of oxygen therapy by ICU physicians and nurses. Ann Intensive Care. 2014;4:23.

5. Helmerhorst HJ, Roos-Blom MJ, van Westerloo DJ, de Jonge E. Association between arterial hyperoxia and outcome in subsets of critical illness: a systematic review, meta-analysis, and meta-regression of cohort studies. Crit Care Med. 2015:43(7):1508-19.

6. Chu DK, Kim LH, Young PJ, Zamiri N, Almenawer SA, Jaeschke R, et al. Mortality and morbidity in acutely ill adults treated with liberal versus conservative oxygen therapy (IOTA): a systematic review and meta-analysis. Lancet. 2018;391(10131):1693-705.

7. Helmerhorst HJ, Arts DL, Schultz MJ, van der Voort PH, Abu-Hanna A, de Jonge $E$, et al. Metrics of arterial hyperoxia and associated outcomes in critical care. Crit Care Med. 2017;45(2):187-95.

8. de Jonge E, Peelen L, Keijzers PJ, Joore H, de Lange D, van der Voort PH, et al. Association between administered oxygen, arterial partial oxygen pressure and mortality in mechanically ventilated intensive care unit patients. Crit Care (London, England). 2008;12(6):R156.

9. Capellier G, Panwar R. Is it time for permissive hypoxaemia in the intensive care unit? Crit Care Resuscitation: J Australas Acad Crit Care Med. 2011;13(3): 139-41.

10. Panwar R, Hardie M, Bellomo R, Barrot L, Eastwood GM, Young PJ, et al. Conservative versus liberal oxygenation targets for mechanically ventilated patients. A pilot multicenter randomized controlled trial. Am J Respir Crit Care Med. 2016;193(1):43-51.

11. Suzuki S, Eastwood GM, Glassford NJ, Peck L, Young H, Garcia-Alvarez M, et al. Conservative oxygen therapy in mechanically ventilated patients: a pilot before-and-after trial. Crit Care Med. 2014;42(6):1414-22. 
12. Asfar $P$, Singer $M$, Radermacher $P$. Understanding the benefits and harms of oxygen therapy. Intensive Care Med. 2015;41(6):1118-21.

13. Gilbert-Kawai ET, Mitchell K, Martin D, Carlisle J, Grocott MP. Permissive hypoxaemia versus normoxaemia for mechanically ventilated critically ill patients. Cochrane Database Syst Rev. 2014;2014(5):Cd009931.

14. Martin DS, Grocott MP. Oxygen therapy in critical illness: precise control of arterial oxygenation and permissive hypoxemia. Crit Care Med. 2013;41(2): 423-32.

15. Angus DC. Oxygen therapy for the critically III. N Engl J Med. 2020;382(11): 1054-6.

16. Girardis M, Busani S, Damiani E, Donati A, Rinaldi L, Marudi A, et al. Effect of conservative vs conventional oxygen therapy on mortality among patients in an intensive care unit. JAMA. 2016;316(15):1583.

17. Brueckl C, Kaestle S, Kerem A, Habazettl H, Krombach F, Kuppe H, et al. Hyperoxia-induced reactive oxygen species formation in pulmonary capillary endothelial cells in situ. Am J Respir Cell Mol Biol. 2006;34(4):45363.

18. Crapo JD. Morphologic changes in pulmonary oxygen toxicity. Annu Rev Physiol. 1986;48:721-31.

19. Davis WB, Rennard SI, Bitterman PB, Crystal RG. Pulmonary oxygen toxicity. N Engl J Med. 1983;309(15):878-83.

20. Reinhart K, Bloos F, König F, Bredle D, Hannemann L. Reversible decrease of oxygen consumption by hyperoxia*. Chest. 1991;99(3):690-4.

21. Sutton ADJ, Bailey M, Bellomo R, Eastwood GM, Pilcher DV. The Association between early arterial oxygenation and mortality post cardiac surgery. Anaesth Intensive Care. 2014;42(6):730-5.

22. Barrot L, Asfar P, Mauny F, Winiszewski H, Montini F, Badie J, et al. Liberal or conservative oxygen therapy for acute respiratory distress syndrome. N Engl J Med. 2020;382(11):999-1008.

23. ICU-ROX. Conservative oxygen therapy during mechanical ventilation in the ICU. N Engl J Med. 2020;382(11):989-98.

24. Schjorring OL, Klitgaard TL, Perner A, Wetterslev J, Lange T, Siegemund M, et al. Lower or higher oxygenation targets for acute hypoxemic respiratory failure. N Engl J Med. 2021;384(14):1301-11.

25. Jansen TC, Bakker J, Kompanje EJ. Inability to obtain deferred consent due to early death in emergency research: effect on validity of clinical trial results. Intensive Care Med. 2010;36(11):1962-5.

26. Helmerhorst HJ, Schultz MJ, van der Voort PH, Bosman RJ, Juffermans NP, de Wilde RB, et al. Effectiveness and clinical outcomes of a two-step implementation of conservative oxygenation targets in critically ill patients: a before and after trial. Crit Care Med. 2016;44(3):554-63.

27. van de Klundert N, Holman R, Dongelmans DA, de Keizer NF. Data resource profile: the Dutch National Intensive Care Evaluation (NICE) Registry of admissions to adult intensive care units. Int J Epidemiol. 2015;44(6):1850-h

28. Herdman M, Gudex C, Lloyd A, Janssen M, Kind P, Parkin D, et al. Development and preliminary testing of the new five-level version of EQ-5D (EQ-5D-5L). Qual Life Res. 2011;20(10):1727-36.

29. Janssen MF, Pickard AS, Golicki D, Gudex C, Niewada M, Scalone L, et al. Measurement properties of the EQ-5D-5L compared to the EQ-5D-3L across eight patient groups: a multi-country study. Qual Life Res. 2013;22(7):171727.

30. Potter JE, McKinley S, Delaney A. Research participants' opinions of delayed consent for a randomised controlled trial of glucose control in intensive care. Intensive Care Med. 2013;39(3):472-80.

31. Alali AS, Temkin N, Vavilala MS, Lele AV, Barber J, Dikmen S, et al. Matching early arterial oxygenation to long-term outcome in severe traumatic brain injury: target values. J Neurosurg. 2019;132(2):537-44.

32. Baekgaard JS, Abback PS, Boubaya M, Moyer JD, Garrigue D, Raux M, et al. Early hyperoxemia is associated with lower adjusted mortality after severe trauma: results from a French registry. Crit Care. 2020;24(1):604.

33. Bellomo R, Bailey M, Eastwood GM, Nichol A, Pilcher D, Hart GK, et al. Arterial hyperoxia and in-hospital mortality after resuscitation from cardiac arrest. Crit Care. 2011;15(2):R90.

34. Hafner C, Pramhas S, Schaubmayr W, Assinger A, Gleiss A, Tretter EV, et al. Brief high oxygen concentration induces oxidative stress in leukocytes and platelets - a randomised cross-over pilot study in healthy male volunteers. Shock. 2021;56(3):384-95.

35. Kilgannon JH, Jones AE, Shapiro NI, Angelos MG, Milcarek B, Hunter K, et al. Association between arterial hyperoxia following resuscitation from cardiac arrest and in-hospital mortality. JAMA. 2010;303(21):2165-71.
36. Demiselle J, Calzia E, Hartmann C, Messerer DAC, Asfar P, Radermacher P, et al. Target arterial PO2 according to the underlying pathology: a minireview of the available data in mechanically ventilated patients. Ann Intensive Care. 2021;11(1):88.

\section{Publisher's Note}

Springer Nature remains neutral with regard to jurisdictional claims in published maps and institutional affiliations.

\section{Ready to submit your research? Choose BMC and benefit from:}

- fast, convenient online submission

- thorough peer review by experienced researchers in your field

- rapid publication on acceptance

- support for research data, including large and complex data types

- gold Open Access which fosters wider collaboration and increased citations

- maximum visibility for your research: over $100 \mathrm{M}$ website views per year

At BMC, research is always in progress.

Learn more biomedcentral.com/submissions 